\title{
Research on the application of 5G technology in the cultivation and construction of educational informatization innovation and entrepreneurship ability
}

\author{
Yang Zhao $^{1}$ \\ ${ }^{1}$ Business management and human resources, Wuhan Business University, Wuhan, Hubei, 430000, China
}

\begin{abstract}
With the increasing popularity of education informatization and the emergence of intelligent learning space, students' demand for personalized, convenient and diversified learning content of innovation and entrepreneurship ability is becoming increasingly prominent. The fifth generation mobile communication $(5 \mathrm{G})$ technology is characterized by its large bandwidth, ultra-high reliability, ultra-low delay and large-scale Internet of things. College Students' innovation and entrepreneurship education is the main theme of modern higher education and an important way to promote the transformation and development of local colleges. The quality of business plan and roadshows is one of the important means of financing for start-ups. Improving the ability of college students to write high- quality business plans and develop roadshows is not only conducive to the scientific evaluation and assessment of students' ability, but also helps to stimulate the enthusiasm of college students for innovation and entrepreneurship, and cultivate their ability of innovation and entrepreneurship. Combined with the characteristics of contemporary college students' innovation and entrepreneurship education, this project analyzes the problems existing in college students' business plan writing and roadshow at this stage, and puts forward the establishment of an innovation and entrepreneurship ability training system based on the rapid development of business plan and roadshow, so as to promote the improvement of College Students' innovation and entrepreneurship ability and provide a strong guarantee for deepening the reform of innovation and entrepreneurship education in Colleges and universities.
\end{abstract}

\section{Introduction}

With the growing social economy and the continuous development of science and technology, China's industrial structure has been continuously optimized, and began to develop in the direction of talent power and manufacturing power. Information technology has penetrated into all aspects of our daily life. Only by strengthening the learning of modern information technology, Internet and cloud computing, can we provide continuous power support for the development of social production. The development of innovation and entrepreneurship education in Colleges and universities should pay attention to the application of information technology to enhance the innovation and entrepreneurship ability of college students. Through the development of education informatization teaching, it can not only promote the innovation and entrepreneurship passion of college students, but also promote students to discuss and exchange the hot and difficult points of innovation and entrepreneurship education through the education informatization practice platform. We should provide timely guidance to students in entrepreneurship education.

\section{The era characteristics of College Students' innovation and Entrepreneurship Education under the background of Education Informatization}

The 21st century is an era of information technology revolution. Global communication technology, sensing technology, control technology and computer information processing technology have achieved rapid development. Education informatization is the backbone of education reform. Its continuous development and progress has changed the process of education modernization, optimized the training path of traditional innovation and entrepreneurship education. The extensive promotion of education informatization has enriched and developed the implementation path and content system of innovation and entrepreneurship education. The development of educational information technology improves the ability of human beings to understand the society to a higher extent, and makes the originally complex and tedious process of education and teaching simple, convenient and scientific. 
In a sense, innovation and entrepreneurship is the need of the rapid development of society in the new era, and is the only way of social modernization. Education informatization is to integrate all kinds of information of social development, constantly analyze the new things of contemporary social change, and actively guide people to cultivate innovative thinking. To carry out innovation and entrepreneurship education for college students is to meet the needs of their own development, make full use of the knowledge, experience and skills brought by information technology, and strive to cultivate compound talents adapting to social development through serious thinking, innovation and positive practice. Therefore, colleges and universities should make full use of the development advantages of modern education informatization, strengthen the propaganda of innovation and entrepreneurship education ideas, and strive to cultivate college students' innovation and entrepreneurship consciousness.

From the perspective of innovation and development, the current innovation and entrepreneurship education in Colleges and universities has the realistic dilemma of cognitive dislocation, insufficient investment and weak platform, resulting in the poor practical effect of innovation and entrepreneurship education, unscientific investment structure and the absence of innovation achievement transformation system. Based on the practical difficulties existing in the practice of innovation and entrepreneurship education, combined with the practical law of innovation and entrepreneurship education and the objective reality of China's higher education system, the author believes that colleges and universities should actively sort out the top-level design of innovation and entrepreneurship education, improve the investment mechanism of innovation and Entrepreneurship education, and improve the quality of innovation and entrepreneurship education by virtue of the strength of the government, enterprises and various social subjects Improve the Incubation Platform of innovation and entrepreneurship education, and enhance the effectiveness and timeliness of innovation and entrepreneurship education in Colleges and universities.

\subsection{Sort out the top-level design of innovation and entrepreneurship education, and clarify the work orientation of innovation and entrepreneurship education}

Combing the top-level design of innovation and entrepreneurship education is the primary implementation strategy of innovation and entrepreneurship education from the perspective of innovation and development, and its core goal is to clarify the work orientation of innovation and entrepreneurship education, so as to provide accurate direction for the practice of innovation and entrepreneurship education in Colleges and universities. First, actively publicize the central government's designated documents and relevant opinions on the development of innovation and entrepreneurship education, accelerate the convergence of consensus on innovation and entrepreneurship education in Colleges and universities, and make it clear that innovation and entrepreneurship education is to improve the teaching system of China's higher education The adjustment and optimization of teaching evaluation and teaching objectives aims to cultivate and continuously improve the innovative consciousness, innovative thinking, innovative ability, entrepreneurial kinetic energy, entrepreneurial vision, entrepreneurial ability of higher education talents, so as to contribute innovative talents to the innovation driven development of our country; second, make full use of traditional media and new media platform to strengthen the model of innovation and entrepreneurship education Through training, lectures, expansion and other activities, we organize innovation and entrepreneurship education exchanges among classes, departments and colleges, so as to further consolidate the psychological foundation of innovation and entrepreneurship education in Guangzhou, To help them grasp the core connotation of innovation and entrepreneurship education, so that they can have a clear goal in practice; third, actively carry out competition activities with the theme of innovation and entrepreneurship education, and mobilize the majority of teachers and students to actively participate in the practice of innovation and entrepreneurship education, so as to improve the participation and coverage of innovation and entrepreneurship education in Colleges and universities.

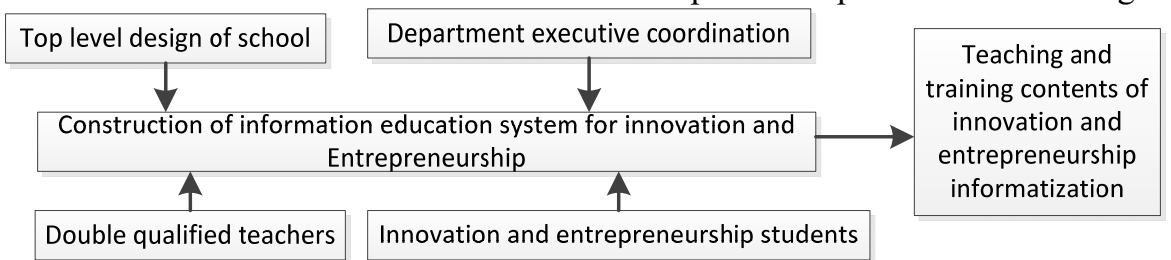

Figure 1 innovation and entrepreneurship informatization teaching path

\subsection{Improve the investment mechanism of innovation and entrepreneurship education, and increase the support of innovation and entrepreneurship education}

Improving the investment mechanism of innovation and entrepreneurship education is the core measure of innovation and entrepreneurship education from the perspective of innovation and development. On the basis of increasing the support of innovation and entrepreneurship education, we should optimize the structure of resource investment, form institutionalization, and realize the sustainable development of innovation and entrepreneurship education. On the one hand, colleges and universities should formulate a scientific, reasonable, executable and sustainable resource investment mechanism for innovation and entrepreneurship education. 
The core contents of the resource investment mechanism mainly include: first, clarify the power of innovation and entrepreneurship education, that is, which direction to invest, There must be a clear type and standard of resource input, and the assessment and evaluation of the effect of resource input should be set to ensure the efficiency of resource input. Second, the expenditure responsibility of innovation and entrepreneurship education should be clear, that is, who will invest the resources, the proportion of the resources invested by government management departments, schools, departments and other main bodies should be clear, and the budget management of resource input should be implemented, To ensure the smooth, efficient and sustainable investment of innovation and entrepreneurship education resources. On the other hand, high efficiency should insist on optimizing the resource input structure of innovation and entrepreneurship education, summarize, analyze, discuss and make collective decisions on the investment direction of innovation and entrepreneurship education, and constantly optimize the direction of investment resources in practice, so as to realize the use of limited resources on the blade; the most important thing is to make clear the performance of innovation and entrepreneurship education resource investment The evaluation mechanism should form a set of scientific, comprehensive, quantifiable and comparable performance evaluation system of innovation and entrepreneurship education resources investment, so as to realize the effective supervision of the use of innovation and entrepreneurship education resources and improve the effectiveness of innovation and entrepreneurship education.

\subsection{Improve the Incubation Platform of innovation and entrepreneurship education, and enhance the practical effect of innovation and entrepreneurship education}

Improving the Incubation Platform of innovation and entrepreneurship education is an important supplementary measure of innovation and entrepreneurship education from the perspective of innovation and development. The core idea is to assist the university management, teachers and students to transform their own research results through the development of incubation platform, so as to realize the cooperation of industry, University and Research University, and finally improve the practical effect of innovation and entrepreneurship education. First of all, based on the actual situation of colleges and universities, reform the existing platform of College Students' innovation and entrepreneurship training plan and the platform of College Employment Guidance Center, including: first, strengthen the professional teachers of the existing platform, enhance the innovation ability and entrepreneurial value of the platform. For the platform of College Students' innovation and entrepreneurship training plan, the participation and contribution of instructors should be included in Teachers' performance appraisal, and teachers should be guided to actively participate in college students' innovation and entrepreneurship training plan projects, so as to improve the effectiveness of existing college students' innovation and entrepreneurship training projects; for the platform of employment guidance center, it is necessary to speed up the construction of a talent team with professional quality, so as to ensure the success of the training In order to make the innovation function and entrepreneurial value of college employment center more prominent, we should help students to carry out innovation and entrepreneurship. Second, it is necessary to reshape the functional orientation of the two existing innovation and entrepreneurship platforms, highlight their innovation guidance function and entrepreneurship incubation function, and match them in terms of human, financial and material support, so as to strengthen the operation and management of the two platforms. Secondly, we should actively carry out cooperation with the government, associations, enterprises and brother universities, jointly build a new platform for innovation and entrepreneurship education in Colleges and universities, strengthen mutual exchanges and cooperation, truly mobilize the positive forces of all aspects to promote the reform process of innovation and entrepreneurship education in Colleges and universities, and improve the effectiveness and effectiveness of innovation and entrepreneurship education practice.

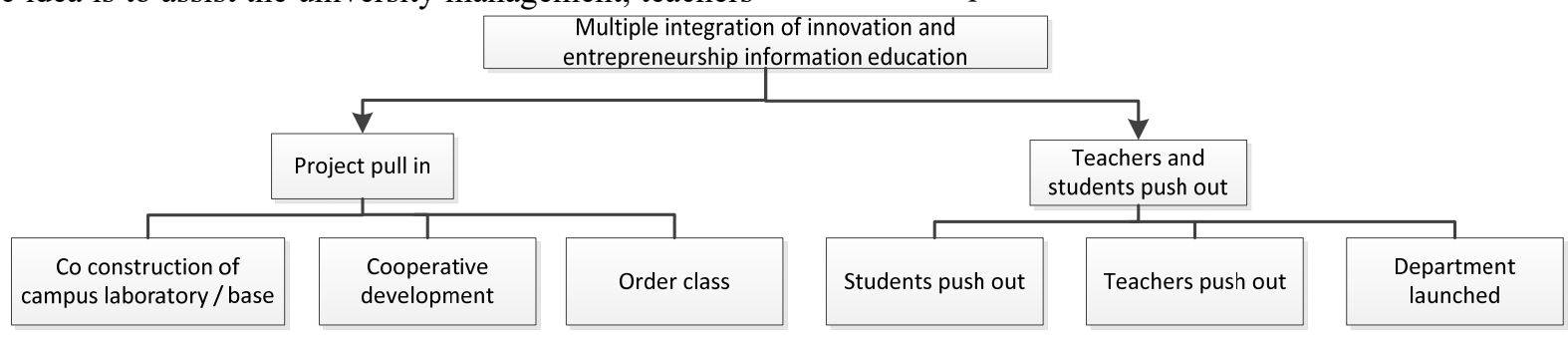

Figure 2 Multiple integration of innovation and entrepreneurship information education 


\section{The diagnostic tool of business plan}

\subsection{Project introspection: clarifying the path of entrepreneurship}

Before the competition and venture financing, the business plan should first be for the participating teams and entrepreneurs themselves. Participating in the competition and running an enterprise are not "passing the house". The participating teams and entrepreneurs should make a detailed analysis of all their resources, known market conditions and preliminary competition strategies with a serious attitude, and put forward a preliminary action plan, so that they can have a clear idea through the business plan. Secondly, the business plan is also a necessary means of venture capital preparation and risk analysis. For start-up venture enterprises, the role of business plan is particularly important. A project in the process of brewing is often very vague. By making a business plan, writing down the positive and negative reasons, and finally deliberating one by one, the participating teams and entrepreneurs can have a clearer understanding of the project and the feasibility of the project.

\subsection{Gathering resources: innovating project management}

Making a scientific business plan can enhance the selfconfidence of the participating teams and entrepreneurs, and make the participating teams and entrepreneurs feel easier to control the project or enterprise, and have a better grasp of the business ideas. Because the business plan provides the status quo and future development direction of the project or enterprise, and also provides a good benefit evaluation system and management monitoring indicators for the project or enterprise. The business plan makes entrepreneurs have rules to follow in their entrepreneurial practice. By describing the development prospects and growth potential of new ventures, the management and employees are full of confidence in the future of the enterprise and individuals, and make clear what projects and activities they want to engage in, so that they can understand what roles they will play, what jobs they will complete, and whether they are competent for these jobs.

\subsection{Access to financing: enhancing competitiveness}

As a comprehensive project plan, the business plan is the process of feasibility analysis of the upcoming venture capital project, and also the publicity of the proposed enterprise and its operation mode to venture capitalists, banks, customers and suppliers, including the enterprise's products, marketing, market and personnel, system, management and other aspects, To a certain extent, it is also a document for the proposed enterprise to carry out publicity and packaging. Designing and writing a high- quality business plan may also have the opportunity to obtain the support and support of the government, enhance the confidence of the participating teams and entrepreneurs themselves, and also enhance the confidence of venture capitalists, partners, employees, suppliers and distributors.

\section{Key elements system of business plan}

\subsection{Design logic of business plan}

Business plan generally includes marketing plan, production plan, financial plan, human resource plan, etc. at the same time, it also puts forward short-term, mediumterm and long-term development path, system design, etc. With the request of "Internet plus" number of students' innovation and entrepreneurship competition, we can use "11 sentences" to illustrate the design logic of a business plan and propose the business mode of the project. One sentence explains your inspiration or motivation (entry point); one sentence explains the market potential (market prospect); one sentence explains what hard needs you meet (products, services, solutions); one sentence explains who else provides these hard needs (competitors); one sentence explains where you provide better than them (advantages); one sentence explains how you maintain your advantages (core competitiveness) How do you let your customers know about your products (Marketing); how much can you make in a certain period (profitability); how many shares do you plan to share and how much investment do you plan to make, What are you going to do (financing needs); in one sentence, how do you plan to return investors (exit mechanism); in one sentence, introduce yourself (team advantage).

\subsection{Key content of business plan}

Project name and brief introduction are important means for participating teams or enterprises to establish the first impression with the competition judges or investors. They must be concise and wonderful, so that the competition judges or investors can quickly establish their understanding and interest in the entrepreneurial project, and they can continue to evaluate or invest in the project. Therefore, when designing the name and introduction of the project, the name of the project should not directly use the name of the company, especially the project at the start-up or creative stage. In a word, it must reflect the positioning and competitiveness of the project.

Therefore, it is necessary to analyze the industry background, development trend, market scale, policies and regulations directly related to the project. Industry market analysis should be specific and targeted, closely related to what needs to be done, avoid vague discussion, and describe what kind of pain point, market demand point and opportunity point have been found under the current market background. In the analysis, if there are existing related products or services, the competition pattern and existing products or services are briefly analyzed in the 
form of data or cases, which shows that the differentiation opportunity of the current project and the current implementation of the project is the best time.

When judging a project and judging whether it has investment value, the main concern of the judges or investors is how much benefits the project can bring to the economic and social development or investors, and the key factor to determine its benefits lies in the project or product itself. Therefore, the positioning of the project must be clear, accurate and irreplaceable. One or two sentences can be used to explain what you are going to do. It's better to provide a simple upstream and downstream diagram of the industrial chain or product function diagram, concise workflow diagram, etc., so that the judges or investors of the competition can have a clear idea of what they are going to do. A project design that appeals to the judges or investors usually includes six elements: large market demand, user recognition, obvious cost advantage, intelligent scale effect, obvious marginal benefit and promotion of industry barriers.

\section{Conclusion}

The purpose of business plan design is to let the competition judges or investors quickly understand the products or projects of the start-up enterprise, and make clear what kind of value the products or projects can create, as well as the benefits the other party can get from them. At the same time, the design of the business plan can help entrepreneurs or business leaders sort out the details of the project, so as to improve the understanding of the project and the implementation efficiency of the project.

\section{Acknowledgment}

Source of project: "Business Plan Writing and Roadshow Course Construction under the concept of Innovation and Entrepreneurship Education" (201802341069) Phased results of the Higher Education Department of the Ministry of Education's Industry-university Cooperative Education Project.

\section{References}

1. UNESCO. World Declaration on Higher Education in the 21st Century: Vision and Action[R/OL].(199810-09)[2017-11-

16].http://www.unesco.org/education/educprog/wch e/

2. declaration_eng.htm.

3. Ramesh Nallapati, Feifei Zhai, and Bowen Zhou. Summarunner: A recurrent neural network based sequence model for extractive summarization of documents. In Thirty-First AAAI Conference on Artificial Intelligence, 2017.

4. Aishwarya Padmakumar and Akanksha Saran. Unsupervised text summarization using sentence embeddings.
5. Romain Paulus, Caiming Xiong, and Richard Socher. A Deep Reinforced Model for Abstractive Summarization. CoRR, 2017.

6. Abigail See, Peter J Liu, and Christopher D Manning. Get to the point: Summarization with pointergenerator networks. arXiv preprint arXiv:1704.04368, 2017. 